\title{
Candida albicans HSP 90: link between protective and auto immunity
}

\author{
RUTH C. MATTHEWS \\ Department of Medical Microbiology, University of Manchester, Oxford Road, Manchester M13 9PT
}

\begin{abstract}
Summary. Heat shock proteins (HSP) are thought to play a role in the aetiology of autoimmune diseases, but are also common targets for the immune response to many infections. Patients recovering from systemic candidosis produce antibodies to Candida albicans HSP 90, both to species-specific epitopes and, more commonly, to epitopes shared with human HSP 90. One such autoreactive antibody was protective in a mouse model of systemic candidosis.
\end{abstract}

\section{Introduction}

Prokaryotic and eukaryotic cells respond to the stress of a sudden rise in temperature by increasing the rate of synthesis of so-called "heat shock proteins" (HSPs). ${ }^{1}$ Insults other than heat can induce synthesis of these proteins and it is now clear that many of them are present in normal cells, where they serve important physiological functions. The term "molecular chaperone" has been applied, signifying their more general role as cellular house-keeping proteins. ${ }^{2}$ Autoreactive T cells that react with mycobacterial HSP 65 have been linked to autoimmune diseases, and increased antibodies to HSPs have been observed in rheumatoid arthritis (HSP 65), ankylosing spondylitis (HSP 90) and systemic lupus erythematosus (HSP 70, HSP 90 and ubiquitin) ${ }^{3,4}$ Members of the HSP 60 , HSP 70 and HSP 90 families are also major targets for the immune system in infections due to bacteria, protozoa and helminths. ${ }^{5}$ HSP 90, together with its breakdown products, is now recognised as an immunodominant antigen in fungal infections and seroconversion to it is associated with recovery from systemic candidosis. ${ }^{6-8}$ As they are highly conserved, cross-reactive immunity against shared epitopes on HSPs could provide immunity against various different micro-organisms. ${ }^{3}$ Boosting immuno-reactivity by repeated exposure to microbial HSPs may assure constantly high levels of immunity, bridging the gap between innate and specific immunity.

In this review, it will be shown that autoreactive antibodies to shared epitopes on Candida albicans and human HSP 90 are commonly produced in patients

The 14th C. L. Oakley Lecture was given at the Meeting of the Pathological Society of Great Britain and Ireland, at the Royal Postgraduate Medical School, Hammersmith Hospital, London, on 9 Jan. 1992. recovering from systemic infection. Cross-reactive antibodies occur in some patients with systemic lupus erythematosus (SLE). These antibodies were protective in a mouse model of systemic candidosis.

\section{The spectrum of candidal infections}

C. albicans is a commensal of the oral cavity and gastrointestinal tract, but in immunocompromised individuals it behaves as an opportunist pathogen, giving rise to superficial or systemic infections. Oral and oesophageal candidosis are frequent clinical features of the acquired immune deficiency syndrome (AIDS) but systemic spread is remarkably rare, despite the presence of severe, progressive immunodeficiency. ${ }^{9,10}$ Similarly, dissemination is rare in chronic mucocutaneous candidosis (CMC), a heterogeneous condition in which protracted superficial candidosis is associated with non-lethal defects in T lymphocytes or macrophages. ${ }^{11}$ In contrast, systemic candidosis is an increasingly common cause of death among immunocompromised and debilitated patients who do not have AIDS. ${ }^{12}$ The mortality of this condition, in culture-proven cases, is about $70 \%{ }^{13,14}$

Because of this very high mortality, some special clinical units with high-risk patients give antifungal agents prophylactically. Occasionally, intensive care or renal units experience an exceptionally high incidence of candidal infections, due to cross-infection between patients with a single strain. ${ }^{15,16}$ Such outbreaks can be recognised by immunoblot fingerprinting or, better still, DNA fingerprinting the isolates collected. ${ }^{17,18}$ If confirmed, existing handwashing reagents should be replaced with fungicidal disinfectants such as Hibisol $^{\circledR}$ or Betadine ${ }^{\circledR}$ and antifungal prophylaxis should be initiated. ${ }^{19}$ With this important exception, most cases of systemic 
candidosis probably arise from invasion by the patient's endogenous strain of yeast.

\section{Immunology}

Many arms of the immune system are involved in host defence against $C$. albicans and their relative importance depends in part on whether the infection is superficial or systemic. Defects in cell-mediated immunity (AIDS, CMC and primary immunodeficiency states) are associated with superficial but not systemic candidosis. ${ }^{20}$ In contrast, mouse models of systemic candidosis have shown the importance of humoral immunity. Athymic mice are no more susceptible to intravenous challenge than euthymic mice. ${ }^{21-23}$ Passive transfer of hyperimmune serum to non-immune mice confers protection, whereas transfer of normal serum or immune lymphocytes does not. ${ }^{24,25}$

Serial immunoblots of multiple sera from patients with culture-confirmed systemic candidosis showed that, among patients with detectable antibodies against $C$. albicans, $92 \%$ had them to the $47-\mathrm{Kda}$ band, $40 \%$ to a $60-\mathrm{Kda}$ band, $27 \%$ to a $92-\mathrm{Kda}$ band and $20 \%$ to a $40-\mathrm{Kda}$ band. ${ }^{14}$ All survivors produced a major antibody response to the 47-K da band, whereas fatal cases had little or no antibody or falling titres. ${ }^{6,14}$ The 47-Kda antigen is a heat-stable breakdown product of the larger $92-\mathrm{Kda}$ antigen which circulates in the sera of these patients. ${ }^{7,14}$ It has been reported independently by two further groups, ${ }^{26,27}$ and appears to be distinct from the $48-52-\mathrm{Kda}$ enolase antigen described by Buckley and co-workers, ${ }^{28,}{ }^{29}$ which has a different pattern of antibody reactivity. ${ }^{30}$ Both the 47-K da and the 40-Kda antigens have now been identified as breakdown products of the $92-\mathrm{Kda}$ antigen. ${ }^{31,32}$ Cloning and sequencing revealed that this was HSP $90{ }^{7}$ There are probably two HSP 90s in C. albicans, one produced constitutively, which on immunoblotting gives rise to the $47-\mathrm{Kda}$ band, and the other heat-inducible, appearing as the $92-\mathrm{Kda}$ band. ${ }^{31}$ Two HSP 90s occur in the yeast Saccharomyces cerevisiae, mice and man. In the case of $S$. cerevisiae, both genes are very closely related and appear to have equivalent functions; growth at higher temperatures requires higher concentrations of either protein. Mammalian HSP 90, which shares $60 \%$ identity with the $S$. cerevisiae protein, effectively complements the yeast double mutant. ${ }^{33}$

Antibody to the 47-Kda antigen was present in patients with CMC and AIDS. ${ }^{20,34}$ If protective, it would help to explain the rarity with which such patients develop systemic candidosis, despite severe superficial infections. Polyclonal B cell activation may be responsible for the frequency with which this antibody is produced in AIDS patients. In a neonate with candidal meningitis, who recovered, antibody to the 47-Kda antigen was the first to appear in the cerebrospinal fluid. ${ }^{35}$ The mother's serum contained IgG antibodies to other candidal antigens, but not to the 47-K da antigen; therefore, the neonate would not have acquired this potentially protective antibody transplacentally.

The $60-\mathrm{Kda}$ band, the second most commonly recognised in systemically infected patients, ${ }^{14}$ is also heat-inducible. ${ }^{36}$ It may correspond to $S$. cerevisiae HSP 60, which shows extensive sequence homology with bacterial HSP $60 .^{37}$ Members of the HSP 60 family are major targets for antibodies in many infections and elevated antibodies to mycobacterial HSP 65 have recently been demonstrated in patients with superficial candidosis. ${ }^{38} \mathrm{~A}$ monoclonal antibody to the $60-\mathrm{Kda}$ antigen of $C$. albicans was not protective in a mouse model of candidal peritonitis. ${ }^{39}$ Preliminary attempts to induce protective immunity in mice against leprosy and tuberculosis by immunisation with mycobacterial HSP 65 failed (M. Colston, D. Young, cited by Watson). ${ }^{40}$ Such experiments do not exclude the possibility that humoral or cell-mediated immunity against certain epitopes on HSP 65 can be protective, but further work will be required to determine this.

\section{Epitope mapping and antibody therapy}

Sera from infected patients, with antibody to the 47-Kda antigen, were used to map epitopes on the major carboxy fragment of $C$. albicans HSP $90 .^{32}$ This method, developed by Geysen et al., ${ }^{41}$ involves the synthesis of a series of short overlapping peptides on polyethylene rods, which are then probed with patients' sera. It detects only continuous epitopes but has the advantage of being independent of predictive algorithms.

C. albicans HSP 90 shows $>50 \%$ direct homology with human HSP 90 and $83 \%$ direct homology with S. cerevisiae HSP $90 .{ }^{7}$ Most of the antibodies produced by these infected patients were directed against highly conserved epitopes, shared with human HSP $90 .^{32}$ Serum from all the patients recognised epitope $C$ (LKVIRK), and epitope B (LSERM) was the second most commonly recognised. Epitope H (DEPAGE), the only C. albicans-specific, carboxy terminal epitope, was the third commonest epitope, recognised by about $50 \%$ of sera from patients. Therefore, autoreactive antibodies are produced commonly in patients recovering from systemic candidosis, without any clinical evidence of autoimmune sequelae. This is surprising since self-tolerance should lead to conserved epitopes being weakly immunogenic, if at all. However, T cells to self-epitopes on HSP 65 have now been shown to exist in normal individuals. ${ }^{42,43}$ Clearly, immunity to shared epitopes on HSPs does not necessarily cause autoimmune disease. Genetic background also strongly determines susceptibility and other unknown environmental factors may affect the $T$ cell repertoire available.

Sera from patients with SLE, which occasionally cross-react with human HSP $90,{ }^{44}$ can also recognise C. albicans HSP 90 and its breakdown products at 47 and $40 \mathrm{Kda}$. The paucity of humoral autoreactivity to 
stress proteins argues against a direct role in the pathogenesis of such disorders. ${ }^{44}$

Epitopes $\mathrm{C}$ and $\mathrm{H}$ were both immunogenic when the synthetic peptide epitope was conjugated to keyhole limpet haemocyanin and used to immunise rabbits. ${ }^{32}$ The resulting rabbit antisera have been used to develop a serological test for systemic candidosis. In dot-immunobinding assays, these epitope-specific probes are superior in both sensitivity and specificity to unfractioned rabbit antiserum to C. albicans. ${ }^{32}$ They are slightly less sensitive than an affinity-purified rabbit antiserum to the $47-\mathrm{Kda}$ antigen, which recognises multiple epitopes but is technically difficult to prepare. ${ }^{45}$ On theoretical grounds, the rabbit antiserum to epitope $H$ is preferable to that raised against epitope $\mathrm{C}$, since the former will not cross-react with other species of HSP 90.

A murine monoclonal antibody was prepared against the conserved, dominant epitope $C$. This, together with patients' sera containing this antibody, was examined in a mouse model of systemic candidosis. ${ }^{36}$ In one of the two patients' sera examined, the only detectable antibody was to the $47-\mathrm{Kda}$ and $40-$ Kda breakdown products of HSP 90, recognising just epitopes $\mathrm{C}$ and $\mathrm{H}$. The monoclonal antibody, given prophylactically, reduced mortality at $24 \mathrm{~h}$ from $100 \%$ to $66 \%$ and, with a less lethal dose of C. albicans, from $60 \%$ to $20 \%$. The patients' sera, both taken before they received antifungal chemotherapy, halved mortality at $24 \mathrm{~h}$. This protective effect was mediated by the immunoglobulin fraction of the serum. No reduction in mortality was observed with normal human serum, the immunoglobulin fraction thereof, or an irrelevant monoclonal antibody.

\section{The role of HSP 90}

Further immunodominant antigens, identified by immunoblotting with infected patients' sera, have now been recognised as HSP 90 homologues in other fungi (C. parapsilosis and Aspergillus fumigatus) and a gram-positive bacterium, Corynebacterium jeikeium. ${ }^{8,31}$ Human HSP 90 is essentially intracellular. It is involved in the assembly and disassembly of proteins into "higher-order structures", and binds to various cellular proteins, keeping them inactive until they have reached their proper intracellular location or have received the correct activation signal. For example, it associates with steroid hormone receptors in their non-ligand-bound state. ${ }^{46}$ In systemic candidosis, a similar, multifunctional HSP 90 circulates in the plasma in large amounts, where it could mimic the biological activities of human HSP 90, but acting in an extracellular rather than an intracellular environment. An example of the pathogenic effects resulting from candidal HSP 90 might be the disseminated intravascular coagulation sometimes associated with systemic candidosis. HSP 90 is immunologically crossreactive with prothrombin and both carry the tripeptide VIR ${ }^{47}$ Antibody to HSP 90 would then be protective because it neutralises these activities. The fungal HSP 90 may be released only when the yeast breaks down, due to autolysis or the host's immune system. This would be comparable to the release of endotoxin during gram-negative septicaemia. Recently, clinical benefit has been demonstrated from the use of a monoclonal antibody to endotoxin in conjunction with antibiotic therapy. ${ }^{48}$

The exact role of human ${ }^{49}$ or fungal HSP 90 in the physiology of the cell remains elusive. In the water mould, Achyla ambisexualis, HSP 90 is a component of a steroid hormone receptor complex involved in the regulation of sexual development. ${ }^{50}$ The female strain produces a steroid hormone, antheridiol, which induces both development changes and HSP 90, the non-hormone binding component of the steroid receptor, in the male strain. C. albicans reproduces asexually. By analogy, candidal HSP 90 could be a component of a hormone receptor involved in cell to cell interaction leading to germination or budding.

\section{Conclusions}

Patients recovering from systemic candidosis invariably seroconvert to C. albicans HSP 90, producing antibodies to epitopes shared with human HSP 90. A monoclonal antibody to a dominant conserved epitope was protective in a mouse model of the infection. Immunity to shared epitopes does not itself lead to autoimmune sequelae, since healthy individuals have autoreactive $T$ cells to HSP 65 and a significant proportion of B cells spontaneously producing autoantibodies to a wide range of self antigens. Cohen and Young have suggested that selected self antigens are dominant because the immunological response to them is already anticipated by preformed regulatory lymphocyte networks. ${ }^{5}$ As a result, the regulatory elements channel the autoimmune response to these dominant self epitopes towards controlled pathways that prevent the development of autoimmune disease.

Human HSP 90 is essentially intracellular, whereas candidal HSP 90 circulates in the plasma in large amounts. It is suggested that antibody is protective because it neutralises the extracellular, fungal HSP 90. In the future we hope to develop a monoclonal antibody to HSP 90 which can be given prophylactically or, in combination with existing antifungal agents, therapeutically.

I thank Professor J. P. Burnie and many other colleagues for their invaluable contributions to this research and gratefully acknowledge the financial support of The Wellcome Trust (R.C.M. is a Wellcome Senior Research Fellow). 


\section{References}

1. Lindquist S, Craig EA. The heat-shock proteins. Anmu Rev Genet 1988; 22: 631-677.

2. Ellis J. Proteins as molecular chaperones. Nature 1987; 328: 378-379.

3. Kaufmann SHE. Heat shock proteins and the immune response. Immunol Today 1990; 11 : 129-136.

4. Cohen IR. Microbial heat-shock protein and autoimmune diseases. In: Neu HC (ed) New antibacterial strategies. Edinburgh, Churchill Livingstone. 1990: 263-268.

5. Cohen IR, Young DB. Autoimmunity, microbial immunity and the immunological homunculus. Immunol Today 1991; 12 $105-110$.

6. Matthews RC, Burnie JP, Tabaqchali S. Immunoblot analysis of the serological response in systemic candidiasis. Lancet $1984 ; 2$ : 1415-1418.

7. Matthews RC, Burnie JP. Cloning of a DNA sequence encoding a major fragment of the 47 kilodalton stress protein homologue of Candida albicans. FEMS Microbiol Lett 1989. 60: $25-30$.

8. Burnie JP, Matthews RC. Heat shock protein 88 and Aspergillus infection. J Clin Microbiol 1991; $29: 2099-2106$.

9. Reichart CM, Kelly VL, Machert AM. Pathogenic features of AIDS. In: DeVita VT, Hellman S, Rosenburg SA (eds) AIDS, etiology, diagnosis, treatment, and prevention. Philadelphia, Lippincott. 1985: 161-184.

10. Eales L-J, Parkin JM. Current concepts in the immunopathogenesis of AIDS and HIV infection. Br Med Bull 1988; 44 38-55.

11. Kirkpatrick CH, Rich RR, Bennett JE. Chronic mucocutaneous candidiasis: model-building in cellular immunity. $A n n$ Intern Med 1971; 74: 955-978.

12. Edwards JE. Invasive candida infections. Evolution of a fungal pathogen. N Engl J Med 1991 ; 324: 1060-1062.

13. Horn $R$, Wong B, Kiehn TE, Armstrong D. Fungemia in cancer hospital: changing frequency, earlier onset, and results of therapy. Rev Infect Dis 1985; 7: 646-655.

14. Matthews RC, Burnie JP, Tabaqchali S. Isolation of immunodominant antigens from sera of patients with systemic candidiasis and characterisation of serological response to Candida albicans. J Clin Microbiol 1987; 25: 230-237.

15. Burnie JP, Odds FC, Lee W, Webster C, Williams JD. Outbreak of systemic Candida albicans in intensive care unit caused by cross infection. $B M J 1985: 290: 746-748$.

16. Burnie JP, Matthews RC, Lee W et al. Four outbreaks of nosocomial systemic candidosis. Epidemiol Infect 1987;99: 201-211.

17. Lee W, Burnie J, Matthews R. Fingerprinting Candida albicans J Immunol Methods 1986; 93: 177-182.

18. Matthews R, Burnie J. Assessment of DNA fingerprinting for rapid identification of outbreaks of systemic candidiasis. BMJ 1989; 298: 354-357

19. Burnie JP, Lee W, Williams JD, Matthews RC, Odds FC Control of an outbreak of systemic Candida albicans. BMJ $1985 ; 291$ : 1092-1093.

20. Matthews R, Burnie J, Smith D et al. Candida and AIDS evidence for protective antibody. Lancet 1988; 2: 263-266.

21. Cutler JE. Acute systemic candidiasis in normal and congenitally thymic-deficient (nude) mice. $J$ Reticuloendothel Soc 1976; 19: 121-124.

22. Rogers TJ, Balish E, Manning DD. The role of thymusdependent cell-mediated immunity in resistance to experimental disseminated candidiasis. J Reticuloendothel Soc 1976; 20: 291-298.

23. Giger DK, Domer JE, Moser SA, McQuitty JT. Experimental murine candidiasis; pathological and immune responses in T-lymphocyte-depleted mice. Infect Immun 1978; 21 : 729 737.

24. Mourad S, Friedman L. Passive immunisation of mice against Candida albicans. Sabouraudia $1968 ; 6$ : 103-105.

25. Pearsall NN, Adams BL, Bunni R. Immunologic responses to Candida albicans. III. Effects of passive transfer of lymphoid cells or serum on murine candidiasis. $J$ Immunol 1978; 120: $1176-1180$.

26. Neale TJ, Muir JC, Drake B. The immunochemical characterisation of circulating immune complex constituents in Candida albicans osteomyelitis by isoelectric focusing immunoblot, and immunoprint. Aust NZ J Med 1987; 17: 201-209.
27. Ferreira RP, Yu B, Niki Y, Armstrong D. Detection of Candida antigenuria in disseminated candidiasis by immunoblotting. J Clin Microbiol 1990; 28: 1075-1078.

28. Strockbine NA, Largen MT, Zweibel SM, Buckley HR Identification and molecular weight characterisation of antigens from Candida albicans that are recognised by human sera. Infect Immun 1984; 43: 715-721.

29. Mason AB, Brandt ME, Buckley HR. Enolase activity associated with a $C$.albicans cytoplasmic antigen. Yeast $1989 ; 5$ Special issue : S231-S239.

30. Strockbine NA, Largen MT, Buckley HR. Production and characterisation of three monoclonal antibodies to Candida albicans proteins. Infect Immun 1984; 43: 1012-1018.

31. Matthews RC. HSP 90, yeasts and Corynebacterium jeikeium. Epidemiol Infect 1991; 107: 273-283.

32. Matthews RC, Burnie JP, Lee W. The application of epitope mapping to the development of a new serological test for systemic candidosis. J Immunol Methods 1991 ; 143: 73-79.

33. Picard D, Khursheed B, Garabedian MJ, Fortin MG, Lindquist S, Yamanoto KR. Reduced levels of hsp 90 compromise steroid receptor action in vivo. Nature 1990; 348: 166-168.

34. Burford-Mason AP, Matthews RC, Williams JRB. Transient abrogation of immunosuppression in a patient with chronic mucocutaneous candidiasis following vaccination with Candida albicans. J Infect 1987; 14: 147-157.

35. Burnie JP, Matthews RC, Watson JG, Milligan DW, Tabaqchali $S$. Analysis of the antibody response developing in an infant with Candida albicans meningitis. J Infect 1986; 12: 79-83.

36. Matthews RC, Burnie JP, Howat D, Rowland T, Walton F. Autoantibody to heat shock protein 90 can mediate protection against systemic candidosis. Immunology $1991 ; 74: 20-24$.

37. Reading DS, Hallberg RL, Myers AM. Characterisation of the yeast HSP60 gene coding for a mitochondrial assembly factor. Nature 1989; 337: 655-659.

38. Ivanyi $L$, Ivanyi $J$. Elevated antibody levels to mycobacterial 65-kDa stress protein in patients with superficial candidiasis. J Infect Dis 1990; 162: 519-522.

39. Matthews RC, Burnie JP, Fox A et al: The diagnostic and therapeutic potential of a monoclonal antibody to the 60kilodalton nuclear antigen of Candida albicans. Serodiag Immunother 1989; 3: 75-86.

40. Watson JD. Leprosy: understanding protective immunity. Immunol Today 1989; 10: 218-221

41. Geysen HM, Rodda SJ, Mason TJ, Tribbick G, Schoofs PG. Strategies for epitope analysis using peptide synthesis. $J$ Immunol Methods 1987; 102: 259-274.

42. Lamb JR, Bal V, Mendez-Samperio $P$ et al. Stress proteins may provide a link between the immune response to infection and autoimmunity. Int Immunol 1989; 1 : 191-196.

43. Munk ME, Schoel B, Modrow S, Karr RW, Young RA, Kaufmann SHE. T lymphocytes from healthy individuals with specificity to self-epitopes shared by the mycobacterial and human 65-kilodalton heat shock protein. J Immunol 1989 ; 143 : 2844-2849.

44. Jarjour WN, Jeffries BD, Davis JS, Welch WJ, Mimura J, Winfield J. Autoantibodies to human stress proteins. Arthritis Rheum 1991; 34: 1133-1138.

45. Matthews RC, Burnie J. Diagnosis of systemic candidiasis by an enzyme-linked dot immunobinding assay for a circulating immunodominant 47-kilodalton antigen. J Clin Microbiol $1988 ; 26: 459-463$

46. Gustafsson J-A, Wikström A-C, Denis M. The non-activated glucocorticoid receptor: structure and activation. J Steroid Biochem 1988; 34: 53-62.

47. Rebbe NF, Ware J, Bertina RM, Modrich P, Stafford DW. Nucleotide sequence of a cDNA for a member of the human $90-\mathrm{kDa}$ heat-shock protein family. Gene $1987 ; \mathbf{5 3}$ : 235-245.

48. Ziegler EJ, Fisher CJ, Sprung CL et al. Treatment of gramnegative bacteremia and septic shock with HA-1A human monoclonal antibody against endotoxin. $N$ Engl $I$ Med 1991 ; 324: 429-436.

49. Hardesty B, Kramer G. The 90,000 dalton heat shock protein, a lot of smoke but no function as yet. Biochem Cell Biol 1989; 67: 749-750.

50. Brunt SA, Riehl R, Silver JC. Steroid hormone regulation of the Achyla ambisexualis 85-kilodalton heat shock protein, a component of the Achyla steroid receptor complex. Mol Cell Biol 1990; 10: 273-281. 